\title{
Environmental tobacco smoke: multicomponent analysis and room-to-room distribution in homes
}

\author{
Göran Löfroth
}

\begin{abstract}
Objective-To evaluate the room-toroom distribution of environmental tobacco smoke (ETS) in two typical homes with low ventilation rates.

Methods - Cigarettes were smoked in one room and airborne tobacco smoke components (nicotine, isoprene, and particles) and the mutagenic activity of the particulate matter were measured simultaneously in that room and several other rooms in the homes.

Results - With the exception of nicotine, the measured components had similar concentrations in all rooms. The nicotine concentrations were much lower in adjacent rooms than in the smoking room. Conclusions - Non-smoking occupants in typical smoking homes will be exposed to ETS in whichever room they stay. Nicotine disappears faster from room air than other ETS components.

(Tobacco Control 1993; 2 : 222-5)
\end{abstract}

\section{Introduction}

Although active smoking is the major determinant for premature disease and death, passive smoking, ie, exposure to environmental tobacco smoke (ETS) has also been linked to significant effects in exposed persons. There is now a consensus in the literature that passive smoking causes an increased risk of heart disease $^{1,2}$ and lung cancer ${ }^{3-5}$, notwithstanding dissenting views from tobacco industry consultants. ${ }^{6}$ Passive smoking in children is also linked to lower respiratory tract illness $s^{5,7}$ and there is growing evidence that it is a major cofactor in the development of allergies and asthma. ${ }^{5,8-11}$

While adults have some opportunity to avoid passive smoking, children are much more restricted in their ability to avoid exposure; if parents or guardians smoke, the child can be exposed to ETS. In the counselling of parents it is often suggested that smoking should not occur near children, which is commonly understood to mean that smoking should not be carried out with children in the lap or in the

Environmental Health Unit, Nordic School of Public Health, Gothenburg, Sweden G Löfroth

Correspondence to: $\mathrm{Dr}$ G Löfroth, Nordic School of Public Health, Box 12133 S-402 42 Gothenburg, Sweden zones in order to conserve energy. The study included the measurement of concentrations of nicotine, isoprene, and particles (which together comprise a reasonable distribution of component types present in ETS), as well as the mutagenic activity of the particulate matter.

\section{Materials and Methods \\ HOMES}

The homes investigated were one 3-bedroom apartment and one 3-storey/3-bedroom townhouse (see figure). The apartment had a floor area of about $74 \mathrm{~m}^{2}$ and a total volume (excluding closed cabinets, bathrooms, etc) of about $140 \mathrm{~m}^{3}$. The townhouse had a base areas of about $55 \mathrm{~m}^{2}$ and a total volume (excluding closed cabinets, bathrooms, etc) of about $300 \mathrm{~m}^{3}$. Smoking did not occur on a routine basis in either of the homes.

\section{SMOKING AND SAMPLING}

Smoking ${ }^{12}$ was performed in the living rooms with a frequency of 1 cigarette every $30 \mathrm{~min}$ in the apartment and 1 cigarette every $20 \mathrm{~min}$ in the townhouse. The smoking was started 1.5 hours before sampling was initiated and continued throughout the sampling period of $200 \mathrm{~min}$. Samples for analysis were collected at the sites shown in the figure at about $1.5 \mathrm{~m}$ above the floor. Each home was investigated twice and the results are given for each investigation.

\section{NICOTINE}

Nicotine was sampled with battery-operated personal pumps (Casella AFC123, Casella London Inc, UK) at a rate of $21 / \mathrm{min}$ and collected on two successive $37 \mathrm{~mm}$ diameter teflon-coated glass fiber filters (TX40HI20WW, Pallflex Products Corp, Putnam, Pennsylvania, USA). The second filter was treated with sodium bisulphate to collect gas-phase nicotine according to the method of Hammond et $a l^{13}$ The filters were extracted with an aqueous $10 \mathrm{M}$ sodium hydroxide solution containing $5 \%$ ethanol. ${ }^{13}$ The basic aqueous solution was then extracted into heptane containing $0.1 \%$ triethylamine. ${ }^{14}$ Isoquinoline was added as an internal standard. ${ }^{15}$ The extracts were analysed for nicotine on a Varian Model 3400 gas chromatograph with a nitrogen detector. The results are given here as the total concentration of nicotine ${ }^{16}$ (ie, the sum of 


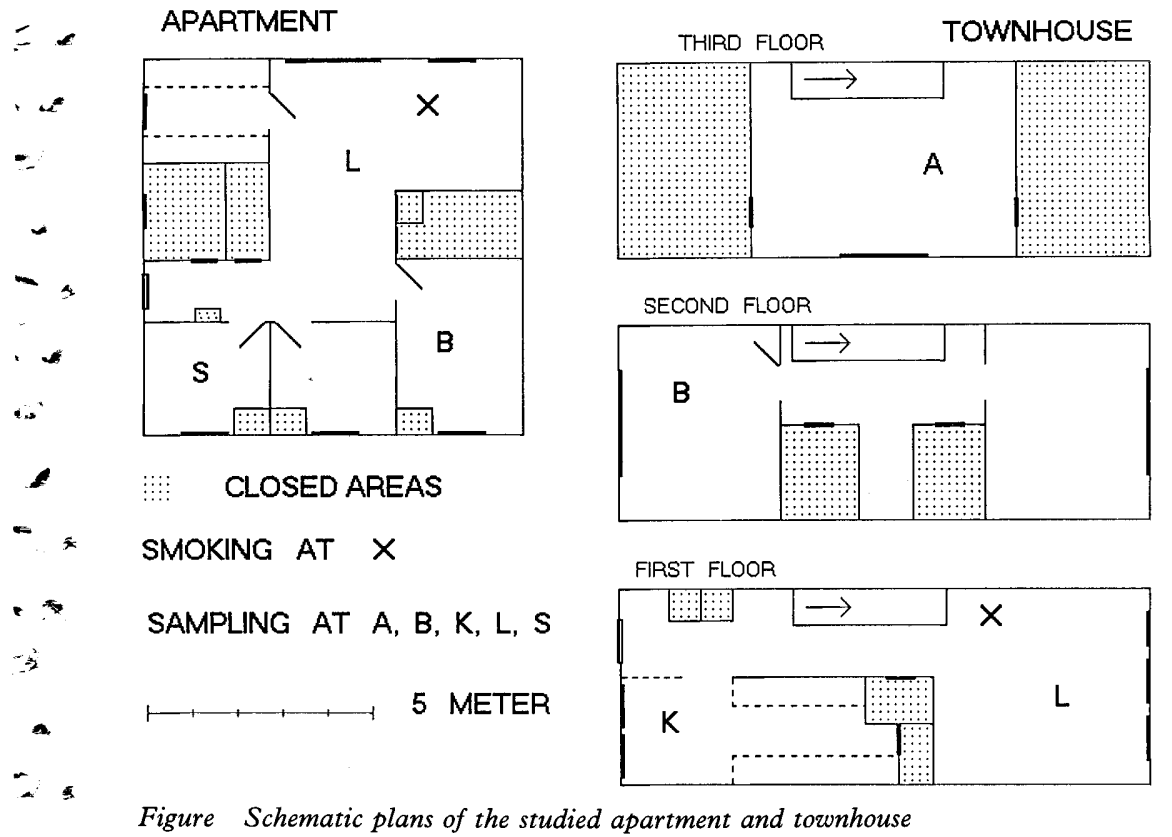

$\checkmark$

nicotine collected on the particulate filter and the gas-phase filter).

ISOPRENE

Isoprene was measured with a portable Photovac 10S50 gas chromatograph (Photovac Inc, Canada) as described elsewhere. ${ }^{17}$ Each room was measured (every $30 \mathrm{~min}$ ) in the apartment. Only one room was measured (every $10 \mathrm{~min}$ ) in the townhouse.

\section{PARTICLES}

The concentration of particles less than $10 \mu \mathrm{m}$ was measured with a TSI Piezobalance Model 3500 (TSI Inc, St Paul, Minnesota, USA). Each sampling location was measured every $30 \mathrm{~min}$ (ie, seven times during the actual sampling period).

$-1$

$\because$

;

\section{MUTAGENICITY}

Particulate matter was collected with batteryoperated pumps (Aircheck sampler, SKC Inc, Eighty Four, Pennsylvania, USA) at a rate of $41 / \mathrm{min}$ on $37 \mathrm{~mm}$ diameter glass-fiber filters (3-A-I/NH, renamed MG160, Stora Filter Products, Grycksbo, Sweden). Filter extraction, sample preparation, and mutagenicity testing in the microsuspension assay have been described elsewhere. ${ }^{18}$ The mutagenicity testing was performed with the Salmonella strain TA98 in the presence of metabolic activation in the form of rat liver S9 (LS-9, Molecular Toxicology, Inc, Annapolis, Maryland, USA). The results are given as revertants $(\mathrm{rev}) / \mathrm{m}^{3}$ air.

\section{VENTILATION RATE}

The ventilation rates were estimated by the rate of disappearance of isoprene and particulate matter after smoking ended. The ventilation rate of the apartment was also measured separately by the disappearance of butane gas emitted into the apartment and analysed by gas chromatography. The ventilation rates were found to be about 0.5 air changes per hour $(\mathrm{ACH})$.

\section{OUTDOOR AIR}

Ambient outdoor particulate matter was collected for mutagenicity assays in the vicinity of the apartment or house on $9 \mathrm{~cm}$ diameter glass-fiber filters at a rate of $50 \mathrm{l} / \mathrm{min}$ during the periods of indoor measurement. The mutagenicity was determined with the same procedure as that used for indoor samples. Particle concentrations were also measured with the TSI Piezobalance instrument before and after the indoor studies. For the days on which indoor samples were collected, community air pollution data were obtained from a rooftop site in the city centre 5 and $20 \mathrm{~km}$ from the apartment and the house.

\section{Results and Discussion}

Tables 1 and 2 summarise the results of the indoor measurements giving the data for each of the replicated studies in each home. The ambient outdoor air was relatively clean: the average outdoor mutagenic activity of the four sampling periods was $60 \mathrm{rev} / \mathrm{m}^{3}$ with individual values of $200,15,<10$, and $<10$. The outdoor concentrations of particles measured before and after the indoor studies were always $<50 \mu \mathrm{g} / \mathrm{m}^{3}$. The data obtained from the community air pollution site corroborated these measurements. Thus, the high indoor concentrations were almost entirely due to the smoking.

Airborne nicotine is a specific indicator for the presence of tobacco smoke and has been used as a tracer in many studies ${ }^{19}$ in addition to measurements of particle concentrations. In other studies it has been found that the nicotine concentration in ambient outdoor air is much less than $1 \mu \mathrm{g} / \mathrm{m}^{3} .^{20}$

The mutagenic activity of the organic extract of airborne particles can be used as a pollution parameter. ${ }^{21}$

Isoprene is a major component of tobacco smoke, ${ }^{17}$ but can have other sources, such as human exhalation. The one or two persons present in the homes during the experiments would have contributed only small amounts of isoprene as the human exhalation is about $0.1-0.4 \mathrm{mg} / \mathrm{h}$ and the tobacco smoke emission is about $5 \mathrm{mg} /$ cigarette. $^{17}$

The concentrations of nicotine decreased drastically with the distance from the living room, where the smoking took place, to other rooms in the homes (tables 1 and 2). This is in contrast to the other pollutants, which were at about the same concentrations in all rooms of the apartment and which only decreased by about $50 \%$ in the most remote room of the townhouse.

The efficient dispersion of ETS to all rooms in the homes, as shown by the analysis of particles and isoprene, implies that occupants cannot escape exposure to ETS if smoking occurs within the home. One might ask how 
Table 1 The concentration of ETS components in two separate studies ( $a$ and $b$ ) in a $140 \mathrm{~m}^{3}$ apartment while smoking one cigarette every $30 \mathrm{~min}$ in the living room.

\begin{tabular}{|c|c|c|c|c|c|c|}
\hline \multirow[b]{2}{*}{ ETS component } & \multicolumn{2}{|c|}{$L$ (living room) } & \multicolumn{2}{|c|}{$B$ (bedroom) } & \multicolumn{2}{|c|}{$S$ (study room) } \\
\hline & $a$ & $b$ & $a$ & $b$ & $a$ & $b$ \\
\hline $\begin{array}{l}\text { Nicotine }\left(\mu \mathrm{g} / \mathrm{m}^{3}\right) \\
\text { Isoprene }\left(\mu \mathrm{g} / \mathrm{m}^{3}\right) \\
\text { Particles }\left(\mu \mathrm{g} / \mathrm{m}^{3}\right) \\
\text { Mutagenicity }\left(\mathrm{rev} / \mathrm{m}^{3}\right)\end{array}$ & $\begin{array}{r}31 \\
50 \\
350 \\
2500\end{array}$ & $\begin{array}{r}35 \\
160 \\
410 \\
2700\end{array}$ & $\begin{array}{r}20 \\
150 \\
350 \\
2600\end{array}$ & $\begin{array}{r}24 \\
160 \\
420 \\
3800\end{array}$ & $\begin{array}{r}8 \\
130 \\
290 \\
2200\end{array}$ & $\begin{array}{r}10 \\
140 \\
330 \\
2600\end{array}$ \\
\hline
\end{tabular}

Table 2 The concentration of ETS components in two separate studies ( $c$ and $d$ ) in a $300 \mathrm{~m}^{3}$ 3-storey/3-bedroom townhouse while smoking one cigarette every 20 min in the living room.

\begin{tabular}{|c|c|c|c|c|c|c|c|c|}
\hline \multirow[b]{2}{*}{ ETS component } & \multicolumn{2}{|c|}{$L$ (living room) } & \multicolumn{2}{|c|}{$K$ (kitchen) } & \multicolumn{2}{|c|}{$B$ (bedroom) } & \multicolumn{2}{|c|}{$A($ attic $)$} \\
\hline & $c$ & $d$ & $c$ & $d$ & $c$ & $d$ & $c$ & $d$ \\
\hline $\begin{array}{l}\text { Nicotine }\left(\mu \mathrm{g} / \mathrm{m}^{3}\right) \\
\text { Isoprene }\left(\mu \mathrm{g} / \mathrm{m}^{3}\right) \\
\text { Particles }\left(\mu \mathrm{g} / \mathrm{m}^{3}\right) \\
\text { Mutagenicity }\left(\mathrm{rev} / \mathrm{m}^{3}\right)\end{array}$ & $\begin{array}{r}63 \\
\mathrm{nd}^{\mathrm{a}} \\
380 \\
3400\end{array}$ & $\begin{array}{c}87 \\
\text { nd } \\
480 \\
5400\end{array}$ & $\begin{array}{c}20 \\
\text { nd } \\
\text { nd } \\
2900\end{array}$ & $\begin{array}{c}32 \\
\text { nd } \\
\text { nd } \\
3100\end{array}$ & $\begin{array}{r}11 \\
180 \\
270 \\
2400\end{array}$ & $\begin{array}{r}9 \\
200 \\
290 \\
3200\end{array}$ & $\begin{array}{c}\text { nd }^{9} \\
240 \\
2200\end{array}$ & $\begin{array}{c}12 \\
\text { nd } \\
280 \\
2100\end{array}$ \\
\hline
\end{tabular}

a $\mathrm{nd}=$ not determined.

the dispersion would be if interior doors are closed instead of open. A closed door would certainly decrease the movement of ETS into the room while the door is closed, but the dispersion will start as soon as the door is opened. It should be noted that ventilation rates of $0.5-1 \mathrm{ACH}$ require several hours to remove ETS from the smoking area; however, the maintenance of a closed door for several hours after someone has smoked is not a practical alternative.

The results of the present study corroborate the finding of an earlier study ${ }^{22}$ in which particulate matter was collected by electrostatic precipitation in children's rooms in smoking and non-smoking families. The result of that study showed that the mutagenic activity in the sampled rooms was very much higher in smoking families than in nonsmoking families and indicated that the fraction of ETS entering the sampled rooms was almost as much as would be expected from an even distribution of mutagenic tobacco smoke particles throughout the homes.

Airborne nicotine is a specific indicator of the presence of tobacco smoke. It has, however, been pointed out previously that nicotine may disappear faster from air than other ETS components, ${ }^{23-25}$ but these suggestions were based on laboratory experiments in chambers with more or less inert surface materials. The present study, in real environments, confirms that nicotine disappears faster from indoor home air than other components, implying that the exposure to nicotine relative to other ETS components may be dependent on the distance between the smoker and the passive smoker.

The major message from this study is that smoking in the home will expose non-smoking occupants to tobacco smoke throughout the home, with potential health consequences. Parents and other child guardians should be enlightened about this fact.

This study has been supported financially by the Swedish Council for Building Research. Mrs Birgitta Bohm contributed nicotine analyses and mutagenicity assays and allowed her townhouse to be polluted twice.
1 Steenland $\mathrm{K}$. Passive smoking and the risk of heart disease. fAMA 1992; 267: 94-9.

2 Taylor AE, Johnson DC, Kazemi H. Environmental tobacco smoke and cardiovascular disease. A position paper from the Council on Cardiopulmonary and Critical Care, American Heart Association. Circulation 1992; 86: 699-702.

3 Pershagen G. Environmental tobacco smoke and cancer. In: Bates DV, Dungworth DL, Lee PN, McClellan RO, Roe FJC, eds. Assessment of inhalation hazards. Berlin: Springer-Verlag, 1989: 275-84.

4 Woodward A, McMichael AJ. Passive smoking and cancer risk: the nature and uses of epidemiological evidence. Eur f Cancer 1991; 27: 1472-9.

5 US Environmental Protection Agency. Respiratory health effects of passive smoking: lung cancer and other disorders. Washington DC: Environmental Protection Agency, 1992. (Publication No EPA/600/6-90/006F.)

6 Lee PN. Environmental tobacco smoke and mortality. Basel: Karger 1992; 224 pp.

7 Samet JM. Environmental tobacco smoke: adverse effects on respiratory infection, respiratory symptoms and lung function. In: Bates DV, Dungworth DL, Lee PN, McClellan RO, Roe FJC, eds. Assessment of inhalation hazards. Berlin: Springer-Verlag, 1989: 265-73.

8 Kershaw CR. Passive smoking, potential atopy and asthma in the first five years. $\mathcal{F} R$ Soc Med 1987; 80: 683-8.

9 Weitzman M, Gortmaker S, Walker DK, Sobol A. Maternal smoking and childhood asthma. Pediatrics 1990; 85: 505-11.

10 Willers S, Svenonius E, Skarping G. Passive smoking and childhood asthma. Allergy 1991; 46: 330-4.

11 Ronchetti R, Bonci E, Cutrera R, DeCastro G, Indinnimeo $\mathrm{L}$, Midulla $\mathrm{F}$ et al. Enhanced allergic sensitisation related to parental smoking. Arch Dis Childhood 1992; 67: 496-500.

12 Ling PI, Löfroth G, Lewtas J. Mutagenic determination of passive smoking. Toxicol Lett 1987; 35:147-51.

13 Hammond SK, Leaderer BP, Roche AC, Schenker M. Collection and analysis of nicotine as a marker for environmental tobacco smoke. Atmospheric Environ 1987; 21: 457-62.

14 Ogden MW, Eudy LW, Heavner DL, Conrad Jr FW, Green CR. Improved gas chromatographic determination, Green CR. Improved gas chromatographic determination
of nicotine in environmental tobacco smoke. Analyst
$1989 ; 114: 1005-8$.

15 Ogden MW. Gas chromatographic determination of nicotine in environmental tobacco smoke: collaborative study. F Assoc Off Anal Chem 1989; 72: 1002-6.

16 Brynnel U, Löfroth $G$. Environmental tobacco smoke in public places. In: Seemayer NH, Hadnagy W, eds. Environmental Hygiene III. Berlin: Springer-Verlag, 1992: 245-8.

17 Löfroth G. Isoprene - A potential indicator for environmental tobacco smoke. Excerpta Med Int Congr Ser 1989; 860: 147-53.

18 Löfroth G, Ling PI, Agurell E. Public exposure to environmental tobacco smoke. Mutat Res 1988; 202: 103-10.

19 Holcomb LC. Indoor air quality and environmental tobacco smoke: Concentrations and exposure. Environ Int 1993; 19: $9-40$

20 Löfroth G. Tobacco smoke in shopping malls and restaurants. Indoor Environ 1993; 2: in press.

21 Lewtas J, Claxton L, Mumford J, Löfroth G. Bioassay of complex mixtures of indoor air pollutants. In: B Seifert HJ van de Wiel, B Dodet, IK O'Neill, eds. Environmental Carcinogens, Vol. 12 Indoor Air. Lyon: International Agency for Research on Cancer, 1993: 85-95.

22 Löfroth G, Lazaridis G. Environmental tobacco smoke: Comparative characterization by mutagenicity assays of 
sidestream and mainstream cigarette smoke. Environ Mutagen 1986; 8: 693-704.

23 Eatough DJ, Hansen LD, Lewis EA. The chemical characterization of environmental tobacco smoke. Environ Technol 1990; 11: 1071-85.

24 Baker RR, Proctor CJ. The origins and properties of environmental tobacco smoke. Environ Int $1990 ; 16$ : 231-45.

25 Nelson PR, Heavner DL Collie BB, Maiolo KC, Ogden $M W$. Effect of ventilation and sampling time on environmental tobacco smoke component ratios. Environ Siri Technol 1992; 26: 1909-15.



